\title{
НАУЧНО-ОНТОЛОГИЧЕСКИЕ ОСНОВЫ ДУХОВНО-ИНТЕЛЛЕКТУАЛЬНОГО ВОСПИТАНИЯ И ОБРАЗОВАНИЯ ЧЕЛОВЕКА НОВОЙ ЭПОХИ (ДИВО-21)
}

\author{
(в контексте современной глобально-земной парадигмы 21-го века)
}

\author{
В. П. Бабич \\ доктор экономических наук, профессор, \\ Президент Всемирного научного ноосферно-онтологического общества
}

За циивилизованный мир!

За выљивание человечества!

Человечество медленно, но упорно движется многотрудными дорогами эволюции и исторического прогресса. Естественное, неугасимое желание людей жить на земной планете в условиях всеобщего мира и благоденствия побуждает каждого человека-землянина к неутомимой активности, целеустремленной деятельности, решению разнообразных текущих и перспективных проблем, свершению малых и больших дел, событий и подвигов. Ведая, а часто и не ведая того, каждый человек и все земляне, вместе взятые, вершат свою историю, руководствуясь и подчиняясь всеобщему Великому закону эволюиии земного бытия.

Могущественными эзотерическими силами природы человечество изначально запрограммировано к постоянному совершенствованию своей жизнедеятельности и на этой главной магистрали земного бытия не может быть длительных остановок и, тем более, обратного движения. Исторический прогресс и эволюцию можно только ускорить или замедлить, но невозможно остановить.

Минувшая история дает убедительные примеры того, что всякая, даже временная стагнация общественной жизни и неспособность к устойчивому, диалектическому совершенствованию влекут за собой ужесточающиеся кризисно-тупиковые ситуации, коллапс и гибель множества государств и империй. По выражению великого немецкого поэта и мыслителя И. Гете «природа не знает остановок в своем движении и казнит всякую бездеятельность».

Спонтанный распад бывшего Советского Союза, в сущности своей, был обусловлен именно отсутствием солидной, социально-обоснованной и реалистичной перспективы своего дальнейшего развития в условиях начавшихся общеземных тенденций всеобщей интеграции и глобализации мирового сообщества. Многие из влиятельных советских политических и государственных деятелей в 80-е годы с потаенной надеждой ожидали мудрых идей, директив и решительных действий со стороны горбачевско-ельцинской когорты новоявленного партийно-государственного истеблишмента.

Однако никто из бывших советских партийно-государственных деятелей и их научно-гуманитарного окружения того времени не сумел или не отважился выработать сложнейшую для условий многонационального государства-лидера мирового развития 20-го века грандиозную программу общественно-исторической реструктуризации и социально-политического обновления.

Поэтому, логически закономерно сработал объективный, эволюционно-исторический роковой приговор, который справедливо называют многие политики геополитической трагедией всего человечества за несоблюдение неписанных, но суровых общеземных императивов разумно-рационального обитания нашей солнечной планеты и гармоничного взаимополезного содействия Человека, Общества и Природы как неразлучных тройственных спарринг-партнеров земного бытия.

Поистине, если оставить в стороне хронологию событий того недавнего времени 80 -х- 90 -х годов и действовавших субъектов-деятелей из числа яростных внутренних и зарубежных антисоветчиков, то станет очевидным, что произошла своеобразная предупредительная обще-ЗЕМНАЯ, ВСЕЛЕНСКАЯ соииально-политическая катастрофа, ультимативно напомнившая всем интегрирующимся и глобализирующимся народам мира об элементарных правилах самосохранения человечества и неукоснительного следования объективным законам и критериям эволюционно-диалектического развития и прогресса.

При этом первым фундаментальным социально-экономическим критерием мудрости политического руководства и устойчивости существования общества-государства является радикальное ограничение субъективизма вседозволенности верховных лидеров всех стран, партийно-государственных структур и социальных сословий и обеспечение научно-гуманитарного соответствия характера и структуры межгосударственных и общественных (межччеловеческих) отношений уровню развития производительных сил общества. Только так можно понять специфику исторически нового, ноосферно-онтологического мировоззрения и миропонимания эволюционно-исторической парадигмы трагически начавшегося 21-го века и 3-го тысячелетия н. э., а вместе с тем недопустимости волевых субъективных решений государственных и общемировых проблем социально-исторической важности. 
Если во времена минувшей истории автономно-суверенного существования государств правящие лидеры и группировки могли действовать сообразно сугубо личным, национал-эгоистическим или кланово-групповым понятиям и соображениям, то ныне наступило совсем иное историческое время интегрирующегося и глобализирующегося мирохозяйства, при котором все верховные деятели больших и малых государств моральноэтически обязаны уяснить и воспринять общегуманистические каноны разумно-рационального сосуществования и взаимополезного сотрудничества.

Ко всеобщему сожалению, проблема полномасштабного практического использования объективно исторических возможностей коренного переустройства межгосударственных и общественных отношений на принципах гуманизации и демократизации мира оказалась пока невоспринятой и непосильной не только для высших государственных деятелей, но и для многоопытных представителей социогуманитарной мировой науки.

Мировое сообщество, включая промышленно развитые страны, вошло в XX1 век и третье тысячелетие в состоянии дрейфующей океанской флотилии, не имеющей ни четко определенных ориентиров, ни основополагающих целей и векторов своего эволюционно-исторического движения. Именно отсутствие солидных научных разработок методологии познания современного мира, идеологической направленности осуществляемых преобразований и всесторонне обоснованных прогнозов ближайшего и отдаленного будущего породило системный мировоззренческий и духовно-интеллектуальный кризис, охвативший все страны и регионы нашей планеты.

В некоторых развитых странах и в том числе в Украине, согласно официальным заявлениям высших государственных деятелей, якобы, идет поиск некоей «национальной идеи развития». Однако уже минуло около 30 лет суверенного существования государства, а ответов на вопросы о том, кто и как ведет этот поиск, на каких принципах она должна строиться и как она согласуется с общемировыми тенденциями развития, не было и в ближайшее время не ожидается. За этим неминуемо следует безграничный и бесконечный плюрализм мнений, суждений и взглядов госчиновников, лидеров и активистов более 100 политических партий и общественных движений при полной неопределенности избранной социально-политической структуры и общегосударственного вектора исторического развития.

В существующей первозданной редакции Конституции Украины в статье 15 незадачливыми авторами этого общенационального документа было написано: «Общественная жизнь в Украине основана на принципах политического, экономическогоиидеологического многообразия. Никакая идеология не может признаваться государством как обязательная. Цензура запрещена». Такой конституционный норматив в полной мере соответствует идеям лихих приверженцев анархизма, типа печально известного “батьки Махно”, действовавшего со своим вооруженным войском во времена послереволюционной разрухи и экономического хаоса под лозунгом «анархия - мать порядка».

Эти идеи и доныне витают в сознании вольнодумных, малограмотных людей, утративших всякую надежду на способность какой-либо власти разумно управлять государством и сложнейшими социально-экономическими процессами. Однако для всех здравомыслящих людей общеизвестно со времен Конфуция и Сократа, что любая ассоциированная, т.е. организованная общественная жизнь и согласованная деятельность многих тысяч и миллионов людей непременно требует властного «дирижерского» (по выражению К. Маркса) управления. И практически оно «по определению» возможно только в случае четко определенной программы совместных взаимодействий всех соучастников и мудрого регулирования частных и общеобъединяющих целей, задач и векторов развития основной, заглавной сюжетной линии. Без этого всякая общность людей утрачивает элементарные признаки ассоциированного объединения и превращается в настоящий сброд современных гуманоидов, живущих «по воле рока» и социально-политической стихии.

Образовавшийся к концу ХХ века общемировой идеологический научно-мировоззренческий вакуум является питательной средой для нездорового и бесплодного плюрализма политических партий, возрождения религиозного фанатизма и национал-экстремизма, дезорганизации многосложной структуры межгосударственных и межчеловеческих отношений. Наиболее опасной для всех развитых и развивающихся стран является современная тенденция духовной дезориентации и деградаџии молодежи, не имеющей ни ясной перспективы, ни вразумительных ответов на каждодневные вопросы о смысле земного обитания и разумных целях приложения своей кипучей энергии.

Один из мудрейших советских ученых и общественных деятелей, лауреат Нобелевской премии, академик АН СССР Жорес И. Алферов (1930-2019) неоднократно подчеркивал, что «без науки и образования у современного государства не может быть будущего...». К этому с полным основанием можно добавить, что эта суровая ультимативная истина нашего смутного времени относится и ко всему человеческому сообществу в целом.

Реальный выход из сложившегося кризисно-тупикового состояния духовного бытия видится в том, чтобы ныне разрозненный потенциал многих прогрессивных научных социо-гуманитарных разработок абсорбировать и синтезировать в единую общечеловеческую систему современных ноосферно-онтологических знанийо разумном, ноосферном построении земного бытия человека и общества в строгом соответствии с ужесточающи- 
мися законами эволюции и окружающей природы. Такой методологический подход позволит, с одной стороны, высвободить человеческое мышление из многовековых оков национал-эгоизма, кланово-группового патриотизма и воинственного гегемонизма, и выйти на уровень всеобщего осознания приоритетов общеземного, исторически нового универсального духовно-материалистического миропонимания и мировоззрения.

С другой стороны, создание научно-теоретических основ Прикладной онтологии, как стройной системы унифицированных, всесторонне апробированных постулатов и норм циивилизованного земного бытия челове-

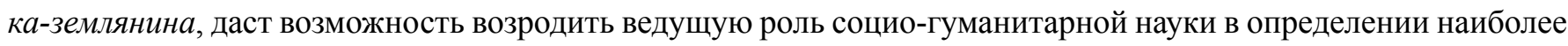
актуальных, текущих и перспективных проблем устойчивого развития каждого государства, каждого региона или общности людей. Современным государственным деятелям и их политическому окружению важно осознать, что не политика и субъективные приоритеты и пристрастия партийно-групповых лидеров должны определять исторические судьбы народов.

Как показывает горький опыт минувшей и нынешней истории, при взаимоагрессивном, “'варварском” построении общественных и межгосударственных отношений неминуемо следует неизлечимость пороков взаимного недоверия, взаимонепонимания и взаимонеуважения, а с ними непреодолимость традиционных недугов агрессивности, воинственности, разноликого терроризма и бандитизма, как реальное проявление аномального человеческого мировоззрения, а с ним и уродливой психологии и морали. По определению одного из немецких ученых И. Зейме (1763-1810) «история, большей частью, представляет собой зрелище, постыдное для человечества2.

Столь нелестная и прискорбная оценка будет оставаться таковой до тех пор, пока каноны и постулаты мировой социо-гуманитарной науки, как единственного чистого родника здраво-мыслия и подлинно человеческой морали, не станут главенствующими и определяющими первоначалами ответственных помыслов и деяний политических и общественных лидеров всех уровней и званий.

Справедливости ради следует сказать, что такая глобальная общеисторическая задача до недавнего времени была непосильной даже для самых мудрых и добропорядочных ученых в силу эволюционной незрелости гуманитарных отраслей знаний, господства властной диктатуры и религиозно-мифического фанатизма. Мир невольно развивался в гнетущей атмосфере тотального субъективизма и вседозволенности властвующих вождейи фюреров, большая часть которых не обладала необходимыми научно-гуманитарными знаниями и потому они действовали сообразно своим личным, субъективно-эгоистичным представлениям и понятиям о добродетели и злодействе. Отсюда следовала нескончаемая вереница войн и массовых трагедий на почве постоянной межнациональной и межрелигиозной конфронтации всех народов мира.

Констатируя эту неприглядную картину мира, английский исследователь Э. Гиббон (1737-1794) писал: «история - это всего лишь журнал регистрации преступлений, глупостей и несчастий человечества». К этому остается добавить, что наиболее тяжкие и трагичные преступления человечества творились под предводительством неистовых вождей-монархов или бесноватых фюреров и под лозунгами борьбы за кланово-групповую веру, за свое национал-шовинистское превосходство и прочие извращения общечеловеческих норм добродетели, человеколюбия и гуманизма.

Появление в 18-19 веке величайших научных открытий в области обществоведения и человекознания способствовали пробуждению общественного сознания и понимания истинных истоков социальной несправедливости и жестокой диктатуры властвующих классов и группировок. В тот период возникли такие отрасли гуманитарной науки, как политэкономия, социология, юриспруденция, психология, педагогика, журналистика, этика и мн. др. Каждая из этих специализированных областей знаний развивалась в соответствии с естественной отраслевой спецификой, углубляя и обогащая суммарный арсенал мировой науки и практики.

Однако ценнейшие, но разрозненные научно-теоретические знания не могли принести человечеству желаемого и долгожданного эффекта в радикальном улучшении земной жизнедеятельности людей, и прежде всего, прекращения войн и насилия, устранения социальной несправедливости и властной диктатуры. Потребовались бурные и во многом трагические революционные события 1917 года, две мировые войны, уникальные террористические акты в японских городах Хиросима и Нагасаки, многолетняя изнурительная холодная война и геополитическая трагедия развала СССР, чтобы на практике ощутить несовершенство и несовместимость господствовавиих систем мировоззрения и аномальность человеческого мыиления.

Многоопытные ученые-гуманисты и прогрессивные политические деятели справедливо считают, что слишком дорогой ценой для человечества достигается общественно-исторический прогресс и интеллектуальное прозрение людей к пониманию объективной необходимости преодоления властного обскурантизма и волюнтаризма. Острая актуальность постановки и практического решения этой глобальной проблемы многократно подтверждается вопиющими фактами и событиями не только нынешнего мирового финансово-экономического кризиса. Еще более опасным, но для многих людей пока невидимым является $\underline{c и с т е м н ы и ̆ ~ д у х о в н ы л и ̆ ~}$ 
кризис, проникший в сознание подрастающих поколений и угнетающий лучшиеморально-волевьле и нравственные качества психологии человека-землянина.

Современные негативные мировоззренческие тенденции, охватившие наиболее промышленно развитые страны, неизбежно приводят к неразрешимости основных социально-экономических проблем и утрате важнейших эволюционно-исторических достижений в области гуманизации образования и воспитания, а также последовательного перехода к цивилизованному, ненасильственному миру.

Без радикальных реформ и коренных преобразований системы духовно-интеллектуального воспитания и образования подрастающих поколений людей, и прежде всего без универсального мировоззренческого базиса у ныне интегрируюшегося человечества нет и не может быть лучшегобудущего. Как писал великий русский писатель и мыслитель Ф. М. Достоевский, «без идеалов, то есть без определенных хоть сколько-нибудь желаний лучшего, никогда не может получиться никакой хорошейдействительности. Даже можно сказать определенно, что ничего не будет, кроме ещче пущзей мерзости».

Наглядным подтверждением этому гениальному тезису является нынешняя общественно-политическая ситуация в Украине, где отсутствует не только общенациональная идея и идеология эволюционного динамичного развития государства, но и открыто пропагандируются анархические принципы пресловутого ультралиберализма, в основу которого положено общеизвестное аморальное правило: «спасение утопающих - дело рук самих утопающих». Точнее можно сказать, что в отсутствие идеологической направленности общественного развития даже самые законопослушные сограждане, не желая того, вынуждены самолично искать свои индивидуальные или кланово-групповые критерии и правила жизнедеятельности и самовыживания.

Совершенно очевидно, что возлагать надежды на пришествие мудрых и гуманных вождей или президентов, как и генсеков ООН является делом безнадежным, достойным наивных и малограмотных людей. Как проникновенно сказано в одной из революционных пролетарских песен начала ХХ века, «никто не даст нам избавленья, - ни бог, ни иарь и ни герой; добьемся мы освобожденья своею собственной рукой». В нынешнее, более спокойное время для избавления ныне живущих и будущих поколений людей от всеобщего кризиса нравственности и самоубийственных тенденций духовной деградации и дебилизации общества требуется не столько «рукой», сколько силой коллективного разума пробудить общественное сознание и добрую волю всех обитателей планеты к труду и созиданию.

Это значит, что в каждой малой или большой общности людей высшие общечеловеческие нормы добродетели и человеколюбия должны последовательно утверждаться как фундаментальные принципь мышиления и поведения каждого индивида-землянина всех наций и народностей. При этом важно в максимальной мере использовать положительные, объективно исторические процессы европейской интеграции и глобализации мира, накопленный теоретический и практический опыт конвергенции конституционно-правовых норм всех развитых или слаборазвитых стран, сохраняя и повсеместно утверждая все лучшие гуманистические признаки национальных культур и обычаев.

Практическое осуществление столь грандиозной глобальной задачи современного духовного ренессанса неразрывно связано с формированием исторически новой модели вселенского, общепланетарного мироустройства, как сообщества грядущей эпохи глобально-земной циивилизации и всемирного единства всех стран и гомо-обитателей планеть Земля.

Такого рода философско-мировоззренческие идеи социально-гармоничного, радикально-эволюционного преобразования стихийно-стохастической структуры человеческого общества впервые были изложены французским социалистом-утопистом Шарлем Фурье в начале 19 века в его фундаментальном исследовании «Теория всемирного единства» (1822 г.). Соответственно этой диалектико-гуманистической теории человечество в своей многовековой истории должно пройти три последовательные эпохи, - дикости, варварства и цุивилизации, на пути многотрудного восхождения от перворождения зачаточных признаков гуманизма к освоению духовноинтеллектуальных принципов и канонов разумно-рационального земного бытия всех стран и народов мира.

Аналогичная и созвучная научная гипотеза возможного радикального оздоровления земной жизнедеятельности всех временных обитателей нашей планеты была сформулирована в 20-м веке гениальным советским ученым, академиком АН СССР В. И. Вернадским, который обосновал перспективу эволюционного перехода человечества от биосферного, стихийно-стохастического к ноосферному, разумно-упорядоченному построению земного бытия. Однако эта уникально-секулярная гипотеза не могла быть воспринята должным образом мировой общественностью в атмосфере всеобщей поглощенности ведущих политических лидеров и их идеологических адептов взаимоагрессивными заботами, связанными с пресловутой «холодной войной», «гонкой вооружений» и тревожным ожиданием возможного начала третьей ядерной мировой войны.

Можно с уверенностью сказать, что к началу XXI века на земной планете резко обострилось эволюционно-историческое противоречие между объективной необходимостью упорядочения международной обстановки и неспособностью правящих партий и влиятельных кланов к разумно-рациональному переходу к нена- 
сильственному, социально-гармоничному миропорядку. С развалом Советского Союза и социалистического лагеря мировое сообщество оказалось в состоянии полной социально-политической неуправляемости и всеобщего «экзистенциального вакуума», когда влиятельные государственные деятели ведущих стран не могут ответить на заглавный вопрос каждого человека-землянина «куда идем, куда мы катимся?» в своем многотрудном земном бытии и эволюционно-диалектическом развитии.

Между тем отечественная и мировая социо-гуманитарная наука обладает достаточным потециалом знаний для разработки и реализации радикальных полномасштабных преобразований и упорядочения земного сосуществования всех стран и народов мира, определения унифицированного, всеобщего смысла жизни всех и каждого человека-землянина. Один из русских философов Е. Н. Трубецкой (1863-1920) примерно 100 лет тому назад писал: «универсальный, всем общий смысл жнизни - вот что объединяет людей в одно целое и спасает личность от внутреннего духовного раздвоения. Вне его царствует хаос и рознь, непримиримая вражда отдельных элементов - как в обществе, так и во внутреннем мире личности».

Однако на всем протяжении минувшего века об «универсальном и всем общзем смысле жизни» можно было только мечтать и фантазировать неисправимым оптимистам и пацифистам, но никак не рассматривать его в качестве практически осуществимого научно-секулярного постулата, консолидирующего мысли и деяния высших государственных деятелей. Совершенно очевидно, что естественное многовековое разрозненное и автономное существование народов мира в «железно» замкнутых географических границах отдельных суверенных государств само по себе порождало пороки подозрительности, недоверия, взаимоагрессивности и взаимозлодейства всеми средствами и способами. Все эти стойкие аморальные свойства человеческой психологии неминуемо проникали и проникают в общественное и личное сознание всех и каждого, порождая неисчислимое множество антагонистических противоречий на всех уровнях межчеловеческих отношений.

Известный философ-гуманист эпохи Возрождения Эразм Роттердамский (1469-1536) писал: «если посмотреть с луны на людскую сутолоку, то можно подумать, будто видишь стаи мух или комаров, дерущихся, воюющих, интригующих, обманьвающих, блудящих, рождающих, падающих, умирающих». В такой сутолоке и повседневной суете люди не задумываются о высоком смысле и ценности жизни, «не ведают, что творят», на что растрачивают свои духовные силы и способности.

Для осмысления и восприятия более полезных и более остроактуальных проблем разумного устройства личного и общественного бытия, обуздания вопиющих пороков бездуховности и откровенного безумия основная масса людей не находит ни сил, ни времени. Этот всеобщий парадокс многократно усиливается и усложняется ныне разразившейся стихией неуправляемой массовой информации и пропаганды, отравляющей сознание людей бациллами ультра-свободы и лжедемократии, вседозволенности и ненаказуемости, за которыми неминуемо следует общая угнетенность духа и доброй воли, неверие в возможность локализации многоликого злодейства и наведения должного порядка в своей земной обители.

«Мир во зле лежит...» гласит одна из древнерусских народных поговорок. Именно она отражает подлинную картину нынешнего постсоветского времени во всех ведущих, промышленно развитых странах, руководство которых по инерции минувшего 20-го века всецело занято проблемами научно-технического прогресса и интенсификации производства в угоду алчного потребления ограниченных природно-сырьевых ресурсов. Многократные и общеизвестные предостережения авторитетных ученых-экологов и прогрессивных представителей социо-гуманитарной науки о надвигающейся опасности апокалипсиса и «конца света» остаются вне надлежащего внимания влиятельных государственных и политических деятелей...

В реальной суровой нынешней действительности, контр-эволюционно и противоестественно сложившейся к началу 21-го века под влиянием самопроизвольной производственной и алчно-потребительской деятельности бывших и нынешних гомо-обитателей планеты, с каждым годом и каждым днем возрастает вероятность вселенской апокалипсической самопогибели человека-землянина и всего человечества.

Несомненно, что для преодоления ультимативной общеземной кризисно-тупиковой ситуации, связанной с духовной и морально-волевой деградацией общественной и индивидуальной жизнедеятельности людей, требуются безотлагательные и консолидированные усилия всех сохранившихся прогрессивных научно-интеллектуальных и политических сил в нескольких важнейших направлениях.

Во-первых, необходимо создать универсальную научную методологию современного изивилизованного, ноосферно-онтологического миропонимания, основанную на всеобщем осознании естественного двуединства и взаимообусловленности материального и духовного бытия.

Во-вторых, разработать глобально-целевую программу Духовно-Интеллектуального воспитания и образования (ДИВО-21) подрастающих поколений сообразно объективным требованиям последовательного эволюционно-исторического перехода человечества к грядущей эпохе общеземной, вселенской цивилизации и ненасильственному миропорядку. 
В-третьих, добиться общественного признания наступившего XXI века столетием духовно-интеллектуального прогресса (ДИП) и приоритетного развития ведущих отраслей социо-гуманитарной науки, образования и всех отраслей культуры, искусства и воспитания новых поколений.

В-четвертых, внести необходимые научно-гуманитарные коррективы в учебные программы школьной и вузовской подготовки молодежи, с тем чтобы придать учебно-воспитательному процессу четкую ноосферную направленность и поэтапное формирование унифищированной системы разумно-созидательного мыслетворчества и адекватного поведения в повседневной жизни и деятельности.

В-пятых, широко использовать прикладные научно-онтологические знания для упорядочения конституционно-правовых норм и законодательных нормативов, регулирующих структуру, соподчинение и взаимосогласованность межгосударственных, межэтнических и иных межчеловеческих отношений.

В-шестых, ходатайствовать перед руководством ООН и ЮНЕСКО об официальном признании научно обоснованной гипотезы эволюционного перехода человечества от эпохи варварства к грядущей эпохе вселенской цивилизации в качестве глобально-исторической парадигмы XXI века и третьего тысячелетия нашей эры.

Практическое осуществление изложенных идей радикального преобразования исторически сложившегося стихийно-стохастического уклада земной жизнедеятельности и аномального сосуществования стран и народов мира позволит в ближайшей перспективе преодолеть негативные тенденции властного обскурантизма и духовно-нравственной деградации людей, выйти на качественно новый, универсально-гуманистический уровень мышления, поведения и общения всех обитателей планеты.

Только объединенными, консолидированными усилиями талантливых ученых-гуманитариев и благоверных педагогов социо-гуманитарного цикла дисциплин в системе среднего и высшего образования возможно совершить эпохально-историческую, духовно-интеллектуальную вселенскую революцию и тем самым повторить «сталинградско»-подобный подвиг в невидимом противостоянии прогрессивных сил нашей планеты разбушевавшейся стихие морально-этического тюрмоил-хаоса и тотально-массовой деменции грядущих поколений.

Наме дело правое! Победа должна быть за нами! ...Или 21-го века не будет вообще!...

Система «ДИВО-21» должна строиться на основе постоянного взаимодействия двух энергетических духовно-секулярных подсистем: духовно-интеллектуальной и духовно-эмоциональной.

При этом духовно-нравственный и морально-психологический базис каждого гомо-человека-землянина формируется непосредственно в семье и даже в утробе матери...

Однако в современно развитом и социально-гармоничном обществе львиная доля проблематики ДИВО подрастающих поколений возлагается на государственные департаменты образования, воспитания и всех отраслей культуры и клерикальные сообщества.

Поэтому если минувший 20-й век вошел в историю как столетие НТП и выдающихся достижений в области материального производства, то начавшийся 21-й век должен стать для эволюционного развития человечества не менее значимым.

\section{Литература}

1. Андрущенко В. П., Михальченко Н. И. Культура, идеология, личность. Киев: Знание. 2002. 365 с.

2. Бабич В. П. Основы современной онтологии: методология, проблемы, перспективы. Харьков: Инжек, 2006.296 с.

3. Бабич В. П. и др. Прикладная онтология: монография. Харьков: Мадрид, 2013. 364 с.

4. Вернадский В. И. Биосфера и ноосфера. Москва: Наука, 1989. 345 с.

5. Клизовский А. И. Основы миропонимания новой эпохи. М. : Фаир-пресс, 2005. 812 с.

6. Дарио Салас. Мораль ХХІ века. Изд. дом «София», 2004. 528 с.

7. Сохань Л. В. и др. Мыстецтво життетворчости особыстости: научно-методическое пособие. 1997.936 с.

8. Amen D. Change Your Braine, Change Your Life. Three Rivers Press. NY, 2001. 265 p.

9. Brzezinski Z. Out of control: Global Turmoil on the Eve of the Twenty-First Century. NY, 1993. 239 p.

10. Holiness H. the Dalai Lama. Ethics for the New Millenium. Riverhead Books. NY, 2003. 325 p.

11. Soros G. George Soros on Globalization. Public Affairs. NY, 2003. 